\title{
Compreendendo as mães de crianças vítimas de abuso sexual: ciclos de violência
}

\author{
Understanding the mothers of children who are \\ victims of sexual abuse: cycles of violence
}

\author{
Samara Silva dos SANTOS \\ Débora Dalbosco DELL'AGLIO'
}

\begin{abstract}
Resumo
O objetivo deste artigo é discutir as características de mães de crianças vítimas de abuso sexual, considerando aspectos como ajustamento emocional, multigeracionalidade e reações maternas frente à revelação. O abuso sexual infantil é considerado um problema de saúde pública e suas conseqüências têm sido foco de interesse de pesquisadores. Entretanto, poucos estudos têm se dedicado a explorar as características maternas envolvidas nesse complexo ciclo de violência. De modo geral, mães de crianças abusadas sexualmente não se configuram como as perpetradoras do abuso, mas de alguma forma encontram-se envolvidas, seja como vítimas ou testemunhas desta situação. Por outro lado, vários fatores influenciam as reações maternas frente à revelação do abuso, tais como a percepção de rede de apoio social e as características de personalidade da mãe, entre outros. Pesquisas têm demonstrado a continuidade da violência entre as gerações, apontando a necessidade de estudos longitudinais sobre o abuso sexual infantil.
\end{abstract}

Unitermos: Abuso de criança. Mães. Traços de personalidades. Violência sexual.

\begin{abstract}
The objective of this article is to discuss the characteristics of mothers of children who are victims of sexual abuse, covering aspects such as emotional reconciliation, multigenerational characteristics and maternal reactions to the disclosure. Child sexual abuse is considered to be a public health problem and its consequences have been a focus of interest of many researchers. However, few studies have been devoted to exploring the maternal characteristics involved in this complex cycle of violence. In general, mothers of sexually abused children are not depicted as perpetrators of the abuse, but in some way they find themselves involved, either as victims of or witnesses to this situation. On the other hand, many factors influence the mothers' reactions when faced with the revelation of the abuse, such as the perceptions of the social support service and the mothers' personality traits, amongst others. Research has demonstrated the continuity of violence from generation to generation, pointing to the need for longitudinal studies on child sexual abuse.
\end{abstract}

Uniterms: Child abuse. Mothers. Personality traits. Sexual abuse.

O objetivo deste artigo é discutir as características de mães de crianças vítimas de abuso sexual e suas reações frente à revelação. $\mathrm{O}$ abuso sexual contra crianças e adolescentes é considerado um problema de saúde pública devido à sua crescente identificação e conseqüente notificação aos órgãos responsáveis

$\boldsymbol{\nabla \nabla \nabla}$

1 Universidade Federal do Rio Grande do Sul, Instituto de Psicologia, Programa de Pós-Graduação em Psicologia. R. Ramiro Barcelos, 2600, Sala 115, Santa Cecília, 90035-003, Porto Alegre, RS, Brasil. Correspondência para/Correspondence to: D.D. DELL'AGLIO. E-mails: <dalbosco@cpovo.net>; <samarass@terra.com.br>. 
(Gonçalves \& Ferreira, 2002; Pfeiffer \& Salvagni, 2005). Segundo a definição de alguns estudos (Azevedo \& Guerra, 1989; Sociedade Brasileira de Pediatria, 2001), o abuso sexual consiste em todo ato ou jogo sexual, relação heterossexual ou homossexual, cujo agressor encontra-se em estágio de desenvolvimento psicossexual mais adiantado do que a criança ou o adolescente. O abusador tem por intenção estimulá-la sexualmente ou utilizá-la para obter satisfação sexual. Apresenta-se sob forma de práticas eróticas e sexuais impostas à criança ou ao adolescente pela violência física, ameaça ou indução de sua vontade. Esse fenômeno violento pode variar desde atos em que não se produz o contato sexual (voyeurismo, exibicionismo, produção de fotos), até diferentes tipos de ações que incluem contato sexual sem ou com penetração.

O abuso sexual pode envolver situações de estupro ou ainda exploração sexual e pornografia, visando lucro. Alguns estudos têm definido o abuso sexual infantil como qualquer toque genital ou comportamento sexual forçado ou imposto, por ameaça ou força física, a uma criança ou adolescente, no qual o perpetrador tenha pelo menos cinco anos a mais do que a vítima (Alexander, Teti \& Anderson, 2000; Leifer, Kilbane \& Kalick, 2004). Esse critério de diferença de idade entre o abusador e a vítima está relacionado a aspectos do desenvolvimento. A criança ou adolescente é envolvida em atividades sexuais que não compreende em sua totalidade e, conseqüentemente, com as quais não está apta a concordar. Segundo Faleiros (2000), sobre a questão do consentimento da vítima, deve-se ter claro que situações de abuso sexual envolvem uma relação de dominação, na qual a criança apresenta poucas condições de reagir porque se encontra sob domínio do abusador. Há um processo de dominação psicológica, e a vítima não pode ser responsabilizada por atos dos quais participa enquanto dominado (Faleiros, 2000). 0 abusador garante sua posição de poder e dominação por meio de um mecanismo de controle baseado em hostilidade e agressividade (Koller \& De Antoni, 2004).

Uma característica singular do abuso sexual refere-se ao fato de que é realizado, freqüentemente, sem o uso de força física, pelo poder, coação e/ou sedução, e por isso não deixa marcas físicas nas vítimas, dificultando a sua identificação. Geralmente, o abuso 596 sexual apresenta uma dinâmica de funcionamento específica. Inicia-se sutilmente e, conforme o abusador adquire a confiança da vítima, os contatos sexualizados tornam-se gradualmente mais íntimos, podendo variar desde um afago até relação sexual genital, oral ou anal (De Antoni \& Koller, 2002; Pires, 2000). A criança pode perceber esses contatos e aproximações como um privilégio, já que uma atenção diferenciada Ihe é dispensada (Pfeiffer \& Salvagni, 2005). Para isso, o perpetrador utiliza seu poder e força física, colocando a criança ou adolescente em situações para as quais não está preparada física nem emocionalmente (Caminha, 2000a, 2000b).

O abuso sexual, para Habigzang e Caminha (2004), pode ser classificado como extrafamiliar ou intrafamiliar, tendo em vista o contexto em que ocorre. Por abuso sexual extrafamiliar compreende-se situações em que a violência ocorre fora do ambiente familiar, envolvendo geralmente pessoas desconhecidas. 0 abuso sexual intrafamiliar ou incesto ocorre dentro da própria família e, algumas vezes, na própria casa da criança. Além disso, essa violência geralmente ocorre mais de uma vez, podendo se estender por anos, e é cometida por uma pessoa próxima, que assume em alguma medida a responsabilidade pelo cuidado da criança (Caminha, 2000b; Habigzang \& Caminha, 2004).

O abuso sexual intrafamiliar torna-se prejudicial à criança vitimada porque envolve uma quebra de confiança com as figuras parentais e/ou de cuidado que, a princípio, deveriam promover segurança, conforto e bem-estar psicológico (De Antoni \& Koller, 2002). Quanto mais próximo for o relacionamento entre ela e o abusador, maior será o sentimento de traição (Sanderson, 2005). Essa quebra de confiança pode não envolver apenas a relação com o abusador, mas afetar também a relação com outros membros da família. Enquanto algumas vítimas encontram estratégias para evitar ou resistir à violência, outras apresentam um padrão de funcionamento caracterizado pelo desamparo aprendido como resposta à exposição continuada de violência. A experiência de violência observada ou vivida na infância passa a ser compreendida como algo incontrolável ou, ainda, natural (Renner \& Slack, 2006).

O abuso sexual tem sido compreendido como uma conseqüência de um ciclo evolutivo de conflitos e agressões entre pais e filhos em que os limites e papéis familiares encontram-se fragilizados e invertidos (Belsky, 1980; Cohen, 2000; Forward \& Buck, 1989). Em uma visão 
sistêmica, o abuso também pode ser considerado um sintoma da crise familiar (Cohen, 2000), que reflete uma incoerência em sua estrutura e um rompimento na integridade das relações familiares (Brendler, Silver, Haber \& Sargent, 1994). Nesse sentido, esses estudos indicaram que há uma dinâmica específica no funcionamento familiar, na qual crianças são vítimas de abuso sexual perpetrados pelos próprios membros ou por pessoas muito próximas. A mãe, assim como os demais envolvidos, pode ser uma pessoa que também precise de ajuda (Cohen \& Mannarino, 2000; Hiebert-Murphy, 1998), pois diante da suspeita ou constatação do abuso de sua filha pode manifestar confusão e ambigüidade (Araújo, 2002).

Oincesto, segundo Forward e Buck (1989), pode ser definido legalmente ou psicologicamente. A definição legal considera apenas as relações sexuais entre indivíduos com graus próximos de parentesco. A definição psicológica é mais abrangente, pois considera qualquer contato abertamente sexual entre pessoas que tenham ou acreditem ter algum grau de parentesco. Nessa perspectiva, o incesto pode ser cometido por padrastos, madrastas, meio-irmãos, avós por afinidade, namorados ou companheiros que morem junto com a mãe ou pai e que exercem o papel de cuidador. Entre as principais características do incesto está o abuso sexual e o vínculo familiar. O incesto entre pai e filha é uma das formas mais freqüentes (Cohen, 2000).

\section{Conseqüências do abuso sexual ao longo de desenvolvimento}

Uma pessoa pode experienciar a violência de três formas: como vítima, como testemunha ou como perpetrador (De Antoni \& Koller, 2002; Koller, 2000). Qualquer uma destas formas pode levar a conseqüências negativas no desenvolvimento, cessando, impedindo, detendo ou retardando-o (Koller, 2000). Diversos estudos têm investigado a problemática do abuso sexual infantil, não somente quanto às repercussões psicopatológicas, mas também quanto aos vários aspectos envolvidos no tratamento de crianças e suas famílias (Cohen \& Mannarino, 2000; Garbarino, Kostelny \& Dubrow, 1991). Este tema também é de interesse de muitos pesquisadores nacionais (Araújo, 2002; Azevedo \& Guerra, 1989; Caminha, 2000a, 2000b; De Antoni \& Koller, 2002; Habigzang \& Caminha, 2004).
Tanto o abuso físico como o sexual são fatores de risco para o desenvolvimento de respostas desadaptativas, não somente na infância e/ou na adolescência, mas também na fase adulta (Reppold, Pacheco, Bardagi \& Hutz, 2002). Entre as conseqüências que o abuso sexual pode acarretar às crianças e adolescentes vitimadas estão o Transtorno de Estresse Pós-Traumático (TEPT), Transtorno Dissociativo, Transtorno Depressivo Maior, Transtorno de Déficit de Atenção e Hiperatividade (TDAH) e Transtornos Alimentares (Belsky, 1993; Caminha, 2000a; Garbarino, et al., 1991). Além disso, crianças e adolescentes expostos à violência sexual podem apresentar ainda comportamentos como sentimentos de culpa e de diferença em relação aos pares, baixa autoestima, timidez, agressividade, medo, embotamento afetivo, isolamento, dificuldade em confiar nos outros, alterações no sono, dores abdominais, fugas de casa, mentiras, sexualidade exacerbada e desesperança em relação ao futuro (Cohen, 2000; De Antoni \& Koller, 2002; Flores \& Caminha, 1994; Habigzang \& Caminha, 2004; Sanderson, 2005).

A literatura tem relacionado história de abuso sexual na infância ao desenvolvimento de psicopatologias na vida adulta (Green, Coupe, Fernandez \& Stevens, 1995; Oates, Tebbutt, Swanston, Lynch \& O'Toole, 1998; Steel, Sanna, Hammond, Whipple \& Cross, 2004). As seqüelas do abuso sexual podem persistir ao longo da vida adulta e estar relacionadas a um padrão de adaptação e ajustamento caracterizados por problemas emocionais, de comportamento e nas relações interpessoais (Bolger \& Patterson, 2003). Além disso, pode afetar diferentemente para alguns indivíduos o conjunto de valores e crenças sobre ser pai ou mãe na vida adulta (Banyard, 1997; Kreklewetz \& Piotrowski, 1998).

Além das seqüelas emocionais do abuso sexual, alguns estudos têm verificado a influência de fatores familiares como mediadores na manifestação dos sintomas na criança. Cohen e Mannarino (2000) concluíram que os sintomas psicológicos de crianças que sofreram abuso sexual são afetados pela cognição individual sobre o evento, mas também por fatores familiares que envolvem a estabilidade do funcionamento familiar. Manifestações de apoio, principalmente por parte da mãe, como acreditar no relato da criança ou adolescente, podem funcionar como mediadoras do impacto negativo do abuso sexual (Forward \& Buck, 1989). 
Elliot e Carnes (2001), em uma revisão da literatura, discutiram os resultados de várias pesquisas sobre reações e interações parentais frente ao abuso sexual infantil. Uma das questões discutidas diz respeito ao fato de a maioria das mães acreditar, pelo menos em parte, nas alegações da criança. Entretanto, mesmo manifestando algum crédito frente à revelação da criança, as mães podem não emitir respostas de apoio e proteção, evidenciando ambivalência ou inconsistência. Esses autores observaram de forma freqüente nos resultados das pesquisas que as interações da mãe com a criança eram baseadas em extremos que variavam da indulgência à punição física. Destacaram, ainda, que o apoio e a proteção dos cuidadores primários estavam associados ao ajustamento emocional e comportamental das crianças abusadas sexualmente.

Pesquisas recentes apontam uma associação entre a capacidade de as crianças lidarem com a experiência de abuso sexual e o fato de as mães acreditarem em seus relatos, e também de darem apoio (Leifer, Kilbane \& Grossman, 2001; Pintello \& Zuravin, 2001). Nesse sentido, o apoio materno recebido pode diminuir a sintomatologia da criança vitimada, pois tem sido apontado como um mediador ou amortecedor frente aos eventos estressores, incluindo o abuso sexual (Steel et al., 2004). Por outro lado, situações de não revelação do abuso por parte da criança, remoção desta para instituições de proteção à infância e adolescência, continuidade do contato da mãe com o abusador após a revelação da criança e, ainda, dependência financeira do companheiro abusador têm sido associadas à falta de apoio materno (Leifer et al., 2001).

Os preditores das crenças e ações de proteção maternas após a revelação de abuso sexual intrafamiliar de suas crianças foram investigados por Pintello e Zuravin (2001). As autoras destacaram quatro preditores: 1) idade materna quando do nascimento do primeiro filho, pois o fato de terem tido filhos na idade adulta e não na adolescência contribuiu para um maior engajamento em ações protetivas e para que acreditassem no relato de abuso; 2) relacionamento e contato entre a mãe e o abusador, sendo que as mães que acreditaram e protegeram suas crianças não tinham contato ou relacionamento com o responsável pelo abuso; 3) conhecimento ou desconfiança prévia à revelação de 598 que algo de estranho estava acontecendo com suas crianças; 4) não emissão de comportamentos sexuais explícitos por parte da criança, pois as mães tendem a acreditar e proteger mais as crianças que não exibem comportamentos sexualizados.

O estudo de Deblinger, Steer e Lippmann (1999) examinou a relação entre fatores maternos, como o estilo parental, e algumas medidas do ajustamento psicossocial de crianças abusadas sexualmente, por exemplo, sintomas de TEPT e depressão. Os resultados demonstraram que crianças que percebiam o comportamento de suas mães como rejeição relataram mais sintomas de depressão do que crianças que percebiam o comportamento materno como cuidadoso e afetuoso. Crianças que percebiam o comportamento de suas mães baseado em culpa e ansiedade apresentaram escores maiores nos sintomas de TEPT e comportamentos externalizantes. Além disso, sintomas de depressão materna foram positivamente associados a sintomas de TEPT nas crianças. Dessa forma, pais deprimidos podem apresentar energia e tolerância diminuída para lidar com seus filhos e também podem experenciar o comportamento de suas crianças como mais sintomáticos do que pais que não se apresentam deprimidos.

Leifer et al. (2001) investigaram o apoio materno em três gerações de famílias de mães que apoiavam e de mães que não apoiavam suas crianças frente à revelação do abuso. Os resultados deste estudo indicaram que um relacionamento familiar intergeracional conturbado ou sem apoio aumentava a vulnerabilidade da criança em situações de abuso, podendo exacerbar os efeitos deste.

No Brasil, Narvaz (2005) realizou um estudo de caso qualitativo com uma mãe vítima de abuso sexual na infância, cujas duas filhas também foram vítimas de abuso sexual. A análise da entrevista indicou que essa mãe manifestou diferentes reações frente à revelação de abuso sexual. Neste caso analisado, a mãe evidenciou descrédito ao tomar conhecimento da situação abusiva de sua filha mais velha. Entretanto, anos mais tarde, quando ocorreu o abuso da segunda filha, manifestou apoio e crédito. Esses resultados evidenciam a complexidade dos fatores envolvidos na dinâmica familiar em situações abusivas, indicando a necessidade de uma visão contextualizada e histórica da realidade da vítima (Koller \& De Antoni, 2004). 
Estudos indicam que mães de crianças abusadas sexualmente geralmente não se configuram como as perpetradoras do abuso (Kreklewetz \& Piotrowski, 1998; Leifer et al., 2004). No entanto, principalmente em situações de abuso sexual intrafamiliar, as mães estão envolvidas de alguma forma, ou por expor suas crianças a companheiros molestadores, ou por não oferecer cuidados básicos em relação a seus filhos, ou ainda por passar juntamente pela situação estressora do abuso. Enquanto algumas mães vítimas de abuso sexual na infância não apresentam dificuldade em proteger suas crianças, para outras essa experiência abusiva na própria infância parece interferir em sua capacidade de evitar situações potencialmente perigosas (Kreklewetz \& Piotrowski, 1998).

\section{Mães de crianças vítimas de abuso sexual}

Pesquisas têm explorado a questão das características e reações maternas em situações de abuso sexual (Alexander et al., 2000; Leifer et al., 2001; Leifer et al., 2004), sendo que alguns estudos enfocam aspectos do relacionamento mãe-criança (Kreklewetz \& Piotrowski, 1998; Leifer et al., 2001; Lewin \& Bergin, 2001), e outros, manifestações de sintomatologia (Green et al., 1995; Steel et al., 2004). No entanto, existem poucos estudos nacionais sobre a temática do abuso sexual que investigam características maternas (Amendola, 2004; Araújo, 2002; Farinati, Biazus \& Leite, 1993; Narvaz, 2005).

Para compreender quem são as mães das meninas vítimas de abuso sexual intrafamiliar é importante resgatar a trajetória de vida dessas mulheres. A literatura as tem descrito como mães com histórias de vida caóticas, com abandonos e violência (Farinati et al., 1993; Padilha \& Gomide, 2004), marcadas por carências afetivas, instabilidade em relação aos cuidadores primários e pouca provisão de apoio mútuo (Amendola, 2004; Farinati et al., 1993; Leifer et al., 2001; Leifer et al., 2004).

Estudos apontam que em famílias abusivas é freqüente a presença de conflitos sexuais no casal (Amendola, 2004; Araújo, 2002; Leifer et al., 2001). As mães, de certa forma, afastam-se da função materna e delegam à filha o papel de mulher da casa (Farinati et al., 1993; Pfeiffer \& Salvagni, 2005). Pesquisas sugerem que o próprio despreparo e desconhecimento dessas mães, no que se refere à educação sexual, propiciam uma tolerância exagerada a atos considerados bizarros e/ou violentos (Amendola, 2004; Flores \& Caminha, 1994). Para Amendola (2004), a relação conjugal dessas mulheres é cercada de cuidados, tanto oferecendo atenção ao companheiro como prevenindo agressões. Além disso, essas mulheres apresentam medo, dependência afetiva e financeira de seus companheiros, e são submissas às ordens da família de origem, demonstrando obediência aos pais e reproduzindo esse comportamento na relação conjugal, ao evitar confrontos.

O relacionamento com o companheiro também foi verificado no estudo de Leifer et al. (2004). Mulheres com história de abuso sexual na infância relataram mais resultado negativo no relacionamento com o companheiro do que as que não apresentavam relato de violência sexual. Mulheres que mencionaram uma maior satisfação no relacionamento com seus companheiros também relataram menos estresse parental (Alexander et al., 2000). Além disso, entre as mulheres com história de abuso sexual na infância e que apresentavam insatisfação conjugal, foi observada maior dependência emocional no relacionamento com suas crianças, demonstrando uma inversão de papéis (Alexander et al., 2000).

Segundo Araújo (2002), no que diz respeito à experiência de atendimento a casos de abuso sexual intrafamiliar, o fato de muitas mães não acreditarem ou mesmo punirem suas filhas pelo acontecido pode ser visto como uma forma de suportar o desmantelamento da unidade familiar e conjugal. A negação das mães pode denunciar uma postura de cumplicidade silenciosa com o agressor, freqüentemente encontrada em casais com conflitos sexuais. Entretanto, cabe ressaltar que, na maioria dos casos de abuso sexual intrafamiliar, as denúncias são efetuadas pelas próprias mães (Habigzang, Koller, Azevedo \& Machado, 2005), que atribuem a demora ou a postergação da denúncia a sentimentos de vergonha (Kreklewetz \& Piotrowski, 1998). O relatório do sistema nacional de combate à exploração sexual infanto-juvenil (Associação Brasileira Multiprofissional de Proteção à Infancia e Adolescência, 2003) refere que, no período de janeiro de 2000 a janeiro de 2003, foram realizadas 1547 denúncias sobre abuso sexual. Do total de denúncias realizadas, 54,0\% representavam casos de abusos intrafamiliares, sendo que em $42,0 \%$ dos casos o pai era o principal suspeito. Em relação 
ao perfil das vítimas, a maioria das denúncias envolveu o sexo feminino $(76,0 \%)$ na faixa etária entre 12 e 18 anos (47,0\%). Uma análise realizada em processos jurídicos do Ministério Público do Rio Grande do Sul por violência sexual, no período de 1992 a 1998, verificou que a denúncia do abuso sexual foi realizada pela mãe da vítima em 37,6\% dos casos, pela própria vítima em 29,0\% dos casos, por outros parentes em 15,1\% e, por instituições, em 6,5\% dos casos. Entretanto, um dado que chama a atenção é que em 61,7\% dos casos alguém informou que já tinha conhecimento da situação abusiva e não denunciou. Em 55,2\% desses casos a mãe era a pessoa que tinha conhecimento da violência sexual (Habigzang et al., 2005).

O estudo de Leifer et al. (2004) teve como objetivo explorar as diferenças entre quatro grupos de mães quanto a algumas áreas do funcionamento materno, por exemplo, continuidade do relacionamento de apego na infância com cuidadores primários, percepção do relacionamento na infância com sua mãe, estilo de apego adulto, consistência e estabilidade do relacionamento adulto heterossexual, experiência adulta de vitimização sexual e/ou física, abuso de substância e sintomatologia relacionada ao trauma. As mães e suas crianças foram divididas em quatro grupos, a saber: a) mães abusadas sexualmente na infância, de crianças que não foram vítimas de abuso sexual; b) mães abusadas sexualmente na infância, de crianças que foram vítimas de abuso sexual; c) mães sem história de abuso sexual na infância, de crianças que não foram vítimas de abuso sexual e d) mães sem história de abuso sexual na infância, de crianças que foram vítimas de abuso sexual. Os resultados indicaram que mães abusadas sexualmente durante a infância apresentaram um rompimento maior com seus cuidadores primários do que aquelas que não tinham história de abuso sexual. As autoras observaram, ainda, que mães com história de abuso sexual na infância cujos filhos também foram abusados sexualmente relataram um tempo menor de convivência com suas próprias mães, do que aquelas sem história de abuso sexual cujos filhos sofreram o abuso. Esses resultados confirmaram os encontrados em estudo anterior (Leifer et al., 2001).

Em relação à percepção do relacionamento na infância com suas próprias mães, a pesquisa de Leifer 600 et al. (2004) verificou que 63\% do grupo de mães abusadas sexualmente na infância, cujos filhos não foram vítimas de abuso sexual, e 43\% do grupo de mães abusadas sexualmente na infância, cujos filhos foram vítimas de abuso sexual, relataram um relacionamento negativo ou inconsistente com sua própria mãe durante a infância, significativamente mais freqüente do que os outros dois grupos de mães. Sobre o estilo de apego adulto, mães com história de abuso sexual na infância relataram mais apego inseguro do que seguro, quando comparadas a mães sem história de violência sexual. Além disso, mães com história de abuso sexual na infância cujos filhos foram abusados sexualmente relataram menos apego seguro e mais apego evitativo, quando comparadas ao grupo de mães sem episódio de abuso sexual na infância.

Estudos apontam que essas mães vivem uma situação de confusão e ambigüidade diante da situação de extrema violência à qual suas crianças foram submetidas, sendo que, muitas vezes, preferem "fechar seus olhos" ao que está sendo explicitado (Amendola, 2004; Farinati et al., 1993). Os sentimentos em relação à filha mostram-se ambivalentes: ao mesmo tempo sentem raiva e ciúmes, e sentem-se culpadas por não tê-las protegido (Araújo, 2002). As interações afetivas com as crianças, nesse contexto, podem acontecer de forma distante e ambivalente (Padilha \& Gomide, 2004).

Mães com história de abuso sexual na infância podem re-experienciar sua própria vivência passada quando tomam conhecimento sobre o abuso sexual de suas crianças (Green et al., 1995; Hiebert-Murphy, 1998; Leifer et al., 2004). O maior sofrimento emocional apresentado por essas mães pode ser um reflexo do efeito do abuso por longo prazo, ou também dos sentimentos de culpa por não terem conseguido proteger seus filhos (Oates et al., 1998). Além disso, questões que envolvem todos os aspectos da revelação do abuso - por exemplo: se houve revelação para a família ou não, se as pessoas para as quais o abuso foi revelado acreditaram ou não, e se houve apoio por parte da família - são importantes para entender todo o contexto do abuso sexual vivido pela mãe e sua conseqüente manifestação de sofrimento emocional ao tomar conhecimento do abuso sexual de sua criança (Hiebert-Murphy, 1998).

Poucos estudos têm investigado aspectos específicos relacionados às características ou ao ajustamento emocional em mães de meninas abusadas sexualmente 
(Amendola, 2004; Oates et al., 1998). Ao analisarem a dinâmica das relações no abuso intrafamiliar, Forward e Buck (1989) descreveram a figura materna como uma cúmplice silenciosa ou como uma pessoa ativamente envolvida. Com relação às mães que silenciam diante dos pequenos sinais e comunicações do abuso sexual de suas filhas, os autores destacaram o abandono emocional da família. Esse abandono ocorre de forma sutil, na medida em que gradualmente a filha assume a responsabilidade pela manutenção da casa, sendo que a transferência de papéis sexuais surge como conseqüência dessa dinâmica. As mães que se encontravam envolvidas de forma ativa no incesto de suas filhas demonstraram ser dependentes, além de apresentarem hostilidade em relação à filha. Para Forward e Buck (1989), há algumas situações em que as mães são forçadas a participar do ato abusivo, sendo ameaçadas de violência ou de abandono. Os autores observaram, nesses casos, a dependência e passividade da mãe, e uma capacidade para tolerar qualquer abuso praticado contra ela e contra seus filhos.

Entre as características de personalidade de mães de crianças abusadas sexualmente apontadas no estudo de Amendola (2004), estavam presentes: permissão para outros tomarem a maioria das importantes decisões, subordinação de suas necessidades às dos outros, relutância em fazer exigências às pessoas das quais dependem, medo exagerado da solidão e de ser abandonada, capacidade limitada de tomar decisões e percepção de desamparo e de incompetência. Essas características sugerem uma dependência emocional evidenciada pela necessidade de estar ligada a determinada pessoa. Assim, situações de violência, como conviver com companheiros agressivos ou abusivos, podem ser toleradas por um longo período de tempo, tendo em vista a necessidade de manter essa ligação.

Muitas das características que mães de meninas abusadas sexualmente apresentam podem também estar associadas a aspectos depressivos. A depressão materna tem sido foco de muitos estudos, não somente pelo fácil acesso dos pesquisadores a essa população, seja na clínica ou na comunidade, como também porque são as mulheres que geralmente assumem os cuidados primários das crianças (Hammen, 2003).

Lewin e Bergin (2001), ao comparar história de abuso sexual, níveis de depressão e ansiedade em mães com crianças vítimas de abuso sexual, não encontraram diferença significativa quanto aos dois grupos: mães com e sem história de abuso sexual na infância. Os resultados indicaram que ambos os grupos apresentaram elevados níveis de depressão e ansiedade. Uma das justificativas apontadas consiste no impacto do processo de investigação do abuso de suas crianças. Ou seja, a intensidade emocional de uma ameaça iminente às suas crianças pode ter sido forte o suficiente para elevar os escores de depressão e ansiedade até mesmo nas mães que não tinham histórias de violência sexual na infância. Entretanto, quando os dados foram comparados a um outro grupo de mães, cujos filhos não haviam sido abusados sexualmente, os resultados em relação aos escores de depressão e ansiedade foram significativamente diferentes. Mães de crianças abusadas sexualmente apresentaram níveis mais altos de depressão e ansiedade e uma diminuição na sensitividade, na cooperação, na aceitação e na acessibilidade durante a interação com suas crianças.

A depressão materna, portanto, pode diminuir a energia física necessária para manter atenção ou supervisão na interação com a criança (Lewin \& Bergin, 2001). Hiebert-Murphy (1998) também comparou a presença de história de abuso sexual na infância em mães com filhos abusados sexualmente, e os resultados apontaram que as mães que experenciaram abuso sexual durante a infância relataram maior sofrimento emocional do que aquelas que não tinham relatado história de abuso sexual. A depressão materna comumente ocorre associada a variáveis pessoais e ambientais que podem atuar como mediadoras ou moderadoras do impacto da depressão, ou ainda podem ser consideradas fatores causais de respostas desadaptativas nas crianças (Hammen, 2003). É importante destacar que a ocorrência de depressão está relacionada a um modelo multicausal, dentro de um contexto de fatores de risco correlacionados.

Algumas mães podem apresentar sintomas de TEPT, como memórias intrusivas de sua própria experiência de abuso sexual na infância, sintomas de depressão e ansiedade após a revelação de abuso sexual de suas filhas (Green et al., 1995). Esses resultados também são compartilhados pela pesquisa de Leifer et al. (2004), na qual mulheres com história de abuso sexual na infância e com crianças abusadas apresentaram um 
resultado maior na escala de sintomatologia que avaliava dissociação, ansiedade, depressão, trauma do abuso sexual, distúrbio de sono e problemas sexuais. Além disso, também verificaram que essas mães relataram maior uso drogas do que mães com crianças sem história de abuso sexual.

Para Amendola (2004), mães que experienciaram o abuso sexual intrafamiliar podem se apresentar dependentes, deprimidas ou, ainda, manifestar TEPT como resposta à situação de estresse. Essa resposta pode ocorrer de forma aguda ou crônica frente à situação de testemunhar ou ser informada sobre o abuso sexual de sua criança. Entre os sintomas típicos que podem se manifestar, destacam-se: a revivência da situação traumática, a sensação de entorpecimento, o medo e a evitação de atividades que recordem essa experiência.

Uma pesquisa qualitativa, baseada em estudo de caso, realizada por Green et al. (1995) com mães de meninas abusadas sexualmente, verificou que as quatro entrevistadas desenvolveram sintomas de TEPT após a revelação de abuso sexual de suas filhas, apresentando ainda comorbidades, como sintomas de depressão. Todas as mães relataram experiência de abuso sexual intrafamiliar, sendo que duas engravidaram e nenhuma revelou à família suas experiências de abuso. Algumas dessas mães re-experienciaram a própria vivência passada quando tomaram conhecimento sobre o abuso sexual de suas crianças (Green et al., 1995).

Estudos apontam sintomas psicológicos em mães que tomaram conhecimento do abuso sexual de suas crianças, como, por exemplo, sintomas de depressão, ansiedade e transtorno de estresse pós-traumático (Green et al., 1995; Hiebert-Murphy 1998; Lewin \& Bergin, 2001). Nesse sentido, um aspecto que pode atuar como um moderador frente à situação de ter uma criança vítima de abuso sexual é a rede de apoio. A rede de apoio social e afetiva proporciona reforço a estratégias de enfrentamento e um ambiente acolhedor (Brito \& Koller, 1999). Além disso, tem sido mencionada como um mediador (amortecedor) frente aos eventos estressores, incluindo o abuso sexual na infância (Steel et al., 2004).

Mulheres que tiveram experiência de abuso 602 sexual na infância apresentaram maiores níveis de insa- tisfação com elas mesmas enquanto mães, e também maior uso de estratégias físicas para resolver conflitos com as crianças (Banyard, 1997). Segundo os resultados da pesquisa de Cohen (1995), que comparou habilidades parentais em mães com e sem história de abuso sexual na infância, foi observado que o abuso influenciou, em certa medida, a percepção de habilidades relacionadas à maternidade. Os resultados sugerem uma dificuldade das mães em manter uma comunicação livre e aberta com suas crianças. Entretanto, há mães que, mesmo tendo sido abusadas sexualmente na infância, conseguem romper esse ciclo de violência, protegendo suas crianças e apresentando resiliência (Leifer et al., 2004). Para Pintello e Zuravin (2001), a concepção de que as mães de crianças abusadas sexualmente são resistentes, culpadas e despreocupadas não pode ser generalizada. Pelo contrário, os resultados da pesquisa que realizaram indicam que a maioria das mães entrevistadas acreditou e providenciou ações de proteção a suas crianças.

O conhecimento sobre o ajustamento emocional de mães de crianças vítimas de abuso sexual é de grande importância para a formação de profissionais que atuam diretamente em ações de acolhimento e intervenção nestas situações. No entanto, estudos empíricos nessa área têm recebido críticas relacionadas aos aspectos metodológicos. Entre elas, pode-se destacar a utilização de amostras muito reduzidas, o que exige precauções quanto à generalização dos resultados (Cohen, 1995; Kreklewetz \& Piotrowski, 1998; Leifer et al., 2001; Pintello \& Zuravin, 2001). Além disso, o grande número de variáveis envolvidas nesses casos dificulta a determinação dos fatores preditores do abuso sexual. Para um maior controle desses aspectos, Cohen (1995) destaca que, para estudos futuros, devem ser investigados grupos clínicos e não clínicos de mulheres com e sem história de abuso sexual na infância, selecionadas aleatoriamente na comunidade. Kreklewetze Piotrowski (1998) também apontam a importância de estudos que focalizem a confiança e a percepção das crianças quanto às práticas educativas maternas e à flexibilidade no estabelecimento de limites durante a adolescência. Leifer et al. (2001) chamam atenção, ainda, para o cuidado com a validade das informações em pesquisas com auto-relatos retrospectivos, tendo em vista que, muitas vezes, a veracidade das informações não pode ser garantida. 


\section{Multigeracionalidade}

Várias pesquisas, ao investigarem a questão da multigeracionalidade em mães de crianças vítimas de abuso sexual, indicaram que freqüentemente as mães relataram histórias de abuso na infância (HiebertMurphy, 1998; Oates et al., 1998). Noventa mulheres com crianças entre cinco e oito anos foram entrevistadas sobre história de abuso sexual na infância, e 22,0\% responderam que sofreram algum tipo de abuso sexual nesta fase do desenvolvimento. A ocorrência de abuso físico por parte do pai também foi investigada, e foi observado que as mulheres com experiência de abuso sexual na infância relataram significativamente mais abuso físico do que aquelas sem história de abuso sexual. $O$ abuso sexual foi cometido em $25,0 \%$ dos casos pela figura paterna, em 12,5\% por um irmão, em 25,0\% por algum parente, em 25,0\% por algum amigo da família e, em 12,5\%, por um estranho. Esses resultados indicaram uma ocorrência maior, nesta amostra, de abuso sexual intrafamiliar (Alexander et al., 2000).

Em um estudo com 102 mulheres atendidas em uma clínica de atendimento a situações de violência que tinham filhos com revelação de abuso sexual nos últimos doze meses, Hiebert-Murphy (1998) identificou que $74 \%$ destas mães revelaram ter, pelo menos, uma experiência de abuso sexual durante a infância e adolescência. Destas, 22\% experenciaram abuso na infância, 22\% na adolescência e 30\% tanto durante a infância quanto na adolescência. Esses resultados podem ser comparados com os do estudo de Oates et al. (1998), realizado na Austrália, no qual $34 \%$ das mães de crianças abusadas sexualmente relataram história de abuso sexual na própria infância, e 12\% das mães de crianças que não haviam sido abusadas sexualmente relataram abuso sexual na própria infância. Dessa forma, foi observada a presença da multigeracionalidade da violência, em especial do abuso sexual, e uma tendência para a ocorrência de abuso sexual na próxima geração. Ou seja, mães que foram abusadas sexualmente em sua própria infância podem apresentar um fator de risco maior para o envolvimento com companheiros abusivos, mantendo, portanto, o ciclo da violência (Flores \& Caminha, 1994; Oates et al., 1998). Além disso, mulheres que sofreram abuso sexual durante a infância podem se tornar mais vulneráveis a estabelecer relações conjugais abusivas, comprometendo de certa forma a capa- cidade de protegerem a si próprias e às suas filhas do abuso sexual (Narvaz, 2005).

Entretanto, ressalta-se que tais estudos verificaram a incidência de história materna de abuso sexual, mas não investigaram questões específicas da manutenção do ciclo de violência. De modo geral, a multigeracionalidade pode ser compreendida como a possibilidade de o adulto reproduzir com crianças da família as experiências de violência vividas em sua própria infância. Nesses casos, as experiências de violência abrangem também o abuso físico, emocional, negligência e abandono (Newcomb \& Locke, 2001). Embora algumas pesquisas evidenciem a repetição de um padrão de relacionamento entre gerações, é necessário destacar que não se trata de um padrão de relacionamento determinista ou universal. Ou seja, o fato de uma criança ser vítima de maus-tratos não significa que, quando adulta, irá repetir tal comportamento com seus filhos, no entanto, existe a possibilidade de esse comportamento aprendido na infância ser repetido com as próximas gerações.

Segundo Kreklewetze Piotrowski (1998), poucas pesquisas têm enfatizado os fatores que contribuem para a recorrência ou para o rompimento do sistema de abuso. O estudo dos efeitos do incesto sobre a maternidade, especialmente considerando os comportamentos protetivos com relação às suas crianças, é uma importante área de estudo, pois contribui para uma compreensão sobre o rompimento desse ciclo de abusos. Uma forma de examinar o ciclo intergeracional de maus-tratos na infância é estudar as experiências de abuso sobre as práticas parentais (Newcomb \& Locke, 2001). Para que se interrompa a revitimização ou a continuidade do abuso, as distorções de relacionamento familiar necessitam ser avaliadas e tratadas (Pfeiffer \& Salvagni, 2005).

O impacto do abuso sexual na infância sobre vários indicadores do funcionamento do papel parental em adultos foi examinado no estudo de Banyard (1997). Foi observado que o abuso sexual na infância estava relacionado a resultados parentais negativos em termos de sentimento sobre si mesmo como pais, e ao uso de estratégias físicas para resolver conflitos com as crianças.

Newcomb e Locke (2001) investigaram a associação entre maus-tratos na infância e práticas parentais em adultos. Os resultados indicaram que, para as mães, 
a experiência de abuso sexual na infância conduziu a um estilo parental caracterizado pela agressividade. Para os autores, a modelação e o reforço são aspectos importantes na internalização dos comportamentos parentais e no ciclo de transmissão intergeracional da violência.

De acordo com alguns estudos apresentados, tanto nacionais (Amendola, 2004; Araújo, 2002; Farinati et al., 1993; Narvaz, 2005) quanto internacionais (Leifer et al., 2001; Leifer et al., 2004), muitas destas mães vivenciaram a violência quando crianças, na forma de negligência, abandono, abuso físico ou até mesmo sexual. Observa-se a continuidade de um padrão de relacionamento que, de alguma forma, é transmitido e repetido no relacionamento conjugal e nas interações com as crianças (Alexander et al., 2000; Banyard, 1997).

\section{Considerações Finais}

O abuso sexual contra crianças e adolescentes é considerado um fenômeno multicausal com repercussões significativas ao longo da vida. A revelação do abuso, geralmente, envolve alterações na dinâmica familiar e provoca uma quebra de confiança da criança para com as figuras parentais. Assim, a situação familiar precisa ser bem investigada, procurando-se esclarecer a participação de outros membros na manutenção do abuso, assim como a presença de conivência e negligência. É importante que, ao se analisar tal situação, todos os aspectos sejam considerados, para uma melhor compreensão da dinâmica do abuso. Essa compreensão pode evitar rotulações a priori de qualquer membro da família, especialmente da mãe, que muitas vezes é acusada de cumplicidade, permitindo entendê-la como parte desse fenômeno e como alguém que também precisa de ajuda. Em casos de abuso sexual intrafamiliar, os procedimentos de avaliação e terapêuticos devem ser ampliados aos demais membros da família.

A partir dos estudos revisados, pode-se observar que, a respeito das características maternas de crianças abusadas sexualmente, são apresentadas duas posições: uma na qual a mãe é vista como cúmplice, e outra na qual é percebida como protetora, na medida em que denuncia e mantém-se ao lado da criança. No entanto, essas duas posições e atitudes maternas podem estar presentes em alguns casos: uma mesma mãe pode estar em uma ou em outra posição em diferentes momentos

604 de sua vida.
Também se observou que vários são os fatores que contribuem para as reações maternas diante da revelação do abuso sexual de suas crianças, tanto do ponto de vista negativo como positivo. Entre os fatores que podem contribuir para uma minimização do abuso e, conseqüentemente, para uma atitude não apoiadora, podem ser citadas as vivências de violência na família de origem, a re-vivência do abuso sexual sofrido na infância, a falta de modelos de família protetiva e apoio familiar, o desejo de ter uma família e mantê-la unida e a dependência emocional e financeira do companheiro. Dessa forma, entende-se que a postura adotada por uma mãe diante dessa situação revela aspectos de sua própria história de vida, assim como as representações que tem sobre família.

Para compreender melhor esse fenômeno, é necessário reconhecer que mães de crianças vítimas de abuso sexual, com ou sem história de abuso na infância, estão freqüentemente lidando com um contexto social caracterizado por pobreza, violência familiar e falta de recursos e apoio. A situação de pobreza, que inclui condições de moradia e de alimentação precárias, bem como a dificuldade de acesso ao mercado de trabalho, expõe estas famílias a uma situação de maior vulnerabilidade. Entretanto, a vulnerabilidade social, como a situação de pobreza, não está necessariamente atrelada ao desenvolvimento de comportamentos vulneráveis nas interações familiares, como a violência intrafamiliar e o abuso sexual. Sabe-se que a violência está presente em diferentes contextos socioeconômicos, mas muitas vezes as famílias encontram recursos internos e externos para modificar esta realidade e apresentar respostas mais adaptativas, superando as desvantagens impostas pela sua situação socioeconômica.

Para uma análise de pesquisas sobre o abuso sexual infantil é importante, portanto, que muitos aspectos sejam considerados, em uma visão mais sistêmica, incluindo desde o contexto social de inserção destas famílias, suas relações com a comunidade, as características das pessoas envolvidas e suas vivências anteriores, entre outras, de forma mais integrada. Estudos específicos sobre as mães de vítimas de abuso são necessários, considerando-se a importância de seu papel na dinâmica familiar e no bem-estar das crianças, na medida em que representam a principal rede de apoio para seus filhos. Dessa forma, destaca-se a necessidade de estudos longitudinais que enfoquem a 
trajetória de vida das mães de crianças abusadas sexualmente e a dinâmica de funcionamento destas famílias, observando as relações entre as diferentes gerações. Este conhe-cimento pode contribuir para a implementação de trabalhos preventivos que possam ajudar as pessoas a sair ou interromper esses ciclos de violência nos quais estão inseridas e, assim, diminuir os efeitos psicossociais que a violência sexual traz às crianças e suas famílias.

\section{Referências}

Associação Brasileira Multiprofissional de Proteção à Infância e Adolescência (2003). Relatório anual do sistemanacional de combate à exploração sexual infanto-juvenil. Rio de Janeiro: ABRAPIA.

Alexander, P. C., Teti, L., \& Anderson, C. L. (2000). Childhood sexual abuse history and role reversal in parenting. Child Abuse \& Neglect, 24 (6), 829-838.

Amendola, M. F. (2004). Mães que choram: avaliação psicodiagnóstica de mães de crianças vítimas de abuso sexual. In M. C. C. A. Prado (Org.), O mosaico da violência: a perversão na vida cotidiana (pp.103-169). São Paulo: Vetor.

Araújo, M. F. (2002). Violência e abuso sexual na família. Psicologia em Estudo, 7 (2), 3-11.

Azevedo, M. A., \& Guerra, V. N. A. (1989). Crianças vitimizadas: a síndrome do pequeno poder. São Paulo: IGLU.

Banyard, V. L. (1997). The impact of childhood sexual abuse and family functioning on four dimensions of women's later parenting. Child Abuse \& Neglect, 21 (11), 1095-1107.

Belsky, J. (1980). Child maltreatment: an ecological integration. American Psychologist, 35 (4), 320-335.

Belsky, J. (1993). Etiology of child maltreatment: a developmental-ecological analysis. Psychological Bulletin, 114 (3), 413-434.

Bolger, K. E., \& Patterson, C. J. (2003). Sequelae of child maltreatment: vulnerability and resilience. In S. S. Luthar (Org.), Resilience and vulnerability: adaptation in the context of childhood adversities (pp.156-181). New York: Cambridge University Press.

Brendler, J., Silver, M., Haber, M., \& Sargent, J. (1994). Doença mental, caos e violência: terapia com famílias à beira da ruptura. Porto Alegre: Artes Médicas.

Brito, R. C., \& Koller, S. H. (1999). Desenvolvimento humano e redes de apoio social e afetivo. In A. M. Carvalho (Org.), O mundo social da criança: natureza e cultura em ação (pp.115-129). São Paulo: Casa do Psicólogo.

Caminha, R. M. (2000a). A violência e seus danos à criança e ao adolescente. In Associação de Apoio à Criança e ao Adolescente (AMENCAR) (Org.), Violência doméstica (pp.43-60). Brasília: UNICEF.
Caminha, R. M. (2000b). Maus-tratos: o flagelo da violência. In V. L. Bemvenutti (Org.), Cadernos de extensão II (pp.37-53). São Leopoldo: Unisinos.

Cohen, C. (2000). O incesto. In M. A. Azevedo \& V. N. A. Guerra (Orgs.), Infância eviolência doméstica: fronteiras do conhecimento (pp.211-225). São Paulo: Cortez.

Cohen, J. A., \& Mannarino, A. P. (2000). Predictors of treatment outcome in sexually abused children. Child Abuse \& Neglect, 24 (7), 983-994.

Cohen, T. (1995). Motherhood among incest survivor. Child Abuse \& Neglect, 19 (2), 1423-1429.

De Antoni, C., \& Koller, S. H. (2002). Violência doméstica e comunitária. In M. L. J. Contini, S. H. Koller \& M. N. S. Barros (Orgs.), Adolescência \& psicologia: concepções, práticas e reflexões críticas (pp.85-91). Rio de Janeiro: Conselho Federal de Psicologia.

Deblinger, E., Steer, R., \& Lippmann, J. (1999). Maternal factors associated with sexually abused children's psychosocial adjustment. Child Maltreatment, 4 (1), 13-20.

Elliot, A. N., \& Carnes, C. N. (2001). Reactions of nonoffending parents to the sexual abuse of their child: a review of the literature. Child Maltreatment, 6 (4), 314-331.

Faleiros, E. T. S. (2000). Repensando os conceitos de violência, abuso e exploração sexual de crianças e de adolescentes. Brasília: Unicef.

Farinati, F., Biazus, D. B., \& Leite, M. B. (1993). Pediatria social: a criança maltratada. Rio de Janeiro: Medsi.

Flores, R. Z., \& Caminha, R. M. (1994). Violência sexual contra crianças e adolescentes: algumas sugestões para facilitar o diagnóstico correto. Revista de Psiquiatria do RS, 16 (2), 158-167.

Forward, S., \& Buck, C. (1989). A traição da inocência: o incesto e sua devastação. Rio de Janeiro: Rocco.

Garbarino, J., Kostelny, K., \& Dubrow, N. (1991). What children can tell us about living in danger? American Psychologist, 46 (4), 376-383.

Gonçalves, H. S., \& Ferreira, H. L. (2002). A notificação da violência intrafamiliar contra crianças e adolescentes por profissionais da saúde. Cadernos de Saúde Pública, 18 (1), 315-319.

Green, A. H., Coupe, P., Fernandez, R., \& Stevens, B. (1995). Incest revisited: delayed pos-traumatic stress disorder in mothers following the sexual abuse of their children. Child Abuse \& Neglect, 19 (10), 1275-1282.

Habigzang, L. F., \& Caminha, R. M. (2004). Abuso sexual contra crianças e adolescentes: conceituação e intervenção clínica. São Paulo: Casa do Psicólogo.

Habigzang, L. F., Koller, S. H., Azevedo, G. A., \& Machado, P. X. (2005). Abuso sexual infantil e dinâmica familiar: aspectos observados em processos jurídicos. Psicologia: Teoria e Pesquisa, 21 (3), 341-348.

Hammen, C. (2003). Risk and protective factors for children of depressed parents. In S. S. Luthar (Org.), Resilience and vulnerability: adaptation in context of childhood adversities (pp.50-75). New York: Cambridge University Press. 
Hiebert-Murphy, D. (1998). Emotional distress among mothers whose children have been sexually abused: the role of a history of child sexual abuse, social support, and coping. Child Abuse \& Neglect, 22 (5), 423-435.

Koller, S. H. (2000). Violência doméstica: uma visão ecológica. In Associação de Apoio à Criança e ao Adolescente (Amencar) (Org.), Violência doméstica (pp.32-42). Brasília: Unicef.

Koller, S. H., \& De Antoni, C. (2004). Violência intrafamiliar: uma visão ecológica. In S. H. Koller (Org.), Ecologia do desenvolvomento humano (pp.293-310). São Paulo: Casa do Psicólogo.

Kreklewetz, C. M., \& Piotrowski, C. C. (1998). Incest survivor mothers: protecting the next generation. Child Abuse \& Neglect, 22 (12), 1305-1312.

Leifer, M., Kilbane, T., \& Grossman, G. (2001). A threegenerational study comparing the families of supportive and unsupportive mothers of sexually abused children. Child Maltreatment, 6 (4), 353-364.

Leifer, M., Kilbane, T., \& Kalick, S. (2004). Vulnerability or resilience to intergeneration sexual abuse: the role of maternal factors. Child Maltreatment, 9 (1), 78-91.

Lewin, L., \& Bergin, C. (2001). Attachment behaviors, depression, and anxiety in nonoffending mothers of child sexual abuse victims. Child Maltreatment, 6 (4), 365-375.

Narvaz, M. G. (2005). Submissão e resistência: explodindo o discurso patriarcal da dominação feminina. Dissertação de mestrado não-publicada, Instituto de Psicologia, Universidade Federal do Rio Grande do Sul, Porto Alegre.

Newcomb, M. D., \& Locke, T. F. (2001). Intergenerational cycle of maltreatment: a popular concept obscured by methodological limitations. Child Abuse \& Neglect, 25 (9), 1219-1240.

Oates, R. K., Tebbutt, J., Swanston, H., Lynch, D., \& O’Toole, B. (1998). Prior childhood sexual abuse in mothers of sexually abuse children. Child Abuse \& Neglect, 22 (11), 1113-1118.

Padilha, M. G. S., \& Gomide, P. I. C. (2004). Descrição de um processo terapêutico em grupo para adolescentes vítimas de abuso sexual. Estudos em Psicologia, 9 (1), 53-61.

Pfeiffer, L., \& Salvagni, E. P. (2005). Visão atual do abuso sexual na infância e adolescência. Jornal de Pediatria, 81 (Supl. 5), 197-204.

Pintello, D., \& Zuravin, S. (2001). Intrafamilial child sexual abuse: Predictors of postdisclosure maternal belief and protective action. Child Maltreatment, 6 (4), 344-352.

Pires, J.M. (2000). Violência na infância: Aspectos clínicos. In Associação de Apoio à Criança e ao Adolescente (Amencar) (Org.), Violência doméstica (pp.32-42). Brasília: Unicef.

Reppold, C. T., Pacheco, J., Bardagi, M., \& Hutz, C. S. (2002). Prevenção de problemas de comportamento e desenvolvimento de competências psicossociais em crianças e adolescentes: uma análise das práticas educativas e dos estilos parentais. In C. S. Hutz (Org.), Situações de risco e vulnerabilidade na infância e na adolescência: aspectos teóricos eestratégias de intervenção (pp.7-51). São Paulo: Casa do Psicólogo.

Renner, L. M., \& Slack, K. S. (2006). Intimate partner violence and child maltreatment: understanding intra and intergenerational connections. Child Abuse \& Neglect, 30 (6), 599-617.

Sanderson, C. (2005). Abuso sexual em crianças: fortalecendo pais e profissionais para proteger crianças de abusos sexuais. São Paulo: M. Books do Brasil.

Sociedade Brasileira de Pediatria. (2001). Guia de atuação frente a maus-tratos na infância e adolescência (2a. ed.). Rio de Janeiro.

Steel, J., Sanna, L., Hammond, B., Whipple, J., \& Cross, H. (2004). Psychological sequelae of childhood sexual abuse: abuse-related characteristics, coping strategies, and attributional style. Child Abuse \& Neglect, 28 (7), 785-801.

Recebido em: 10/10/2006

Versão final reapresentada em: 26/3/2007

Aprovado em: 3/7/2007 